\title{
Expression of catalytic proteasome subunits in the gut of patients with Crohn's disease
}

\author{
Alexander Visekruna - Nadia Slavova - Sonja Dullat • \\ Jörn Gröne • Anton-Josef Kroesen • Jörg-Peter Ritz • \\ Heinz-Johannes Buhr • Ulrich Steinhoff
}

Accepted: 19 February 2009/Published online: 10 March 2009

(C) The Author(s) 2009. This article is published with open access at Springerlink.com

\begin{abstract}
Background and purpose Activation of the transcription factor NF- $\mathrm{kB}$ by proteasomes and subsequent nuclear translocation of cytoplasmatic complexes play a crucial role in the intestinal inflammation. Proteasomes have a pivotal function in NF- $\kappa$ B activation by mediating degradation of inhibitory $\mathrm{I} \kappa \mathrm{B}$ proteins and processing of $\mathrm{NF}-\kappa \mathrm{B}$ precursor proteins. This study aims to analyze the expression of the human proteasome subunits in colonic tissue of patients with Crohn's disease.

Materials and methods Thirteen patients with Crohn's disease and 12 control patients were studied. The expression of immunoproteasomes and constitutive proteasomes was examined by Western blot analysis, immunoflourescence and quantitative real-time PCR. For real-time PCR, AK2C was used as housekeeping gene.

Results The results indicate the influence of the intestinal inflammation on the expression of the proteasomes in Crohn's disease. Proteasomes from inflamed intestine of patients with Crohn's disease showed significantly increased expression of immunosubunits on both protein and mRNA levels. Especially, the replacement of the
\end{abstract}

A. Visekruna $(\bowtie) \cdot$ N. Slavova $\cdot$ S. Dullat $\cdot$ J. Gröne $\cdot$

A.-J. Kroesen - J.-P. Ritz - H.-J. Buhr

Department of Surgery I, Charité-Medical School,

Campus Benjamin Franklin,

Hindenburgdamm 30,

12200 Berlin, Germany

e-mail: alexander.visekruna@charite.de

U. Steinhoff

Max-Planck Institute of Infection Biology,

Charitéplatz 1,

10117 Berlin, Germany constitutive proteasome subunit $\beta 1$ by inducible immunosubunit $\beta$ li was observed in patients with active Crohn's disease. In contrast, relatively low abundance of immunoproteasomes was found in control tissue.

Conclusions Our data demonstrate that in contrast to normal colonic tissue, the expression of immunoproteasomes was evidently increased in the inflamed colonic mucosa of patients with Crohn's disease. Thus, the chronic intestinal inflammation process in Crohn's disease leads to significant alterations of proteasome subsets.

Keywords Crohn's disease · Inflammatory bowel disease $\cdot 26 \mathrm{~S}$ proteasome $\cdot 20 \mathrm{~S}$ proteasome $\cdot \mathrm{NF}-\mathrm{kB}$

\section{Introduction}

Although the etiology of Crohn's disease (CD) still remains partially unclear, substantial advances have been made recently in both understanding of the molecular pathogenesis and also in the development of new therapeutic strategies. The uncontrolled activation of proinflammatory effector $\mathrm{CD}^{+} \mathrm{T}$ cells seems to be a pivotal pathogenic mechanism associated with initiation and perpetuation of the inflammatory process. Activation of Th1 $\mathrm{CD}^{+} \mathrm{T}$ cells as well as of macrophages and dendritic cells leads to the increased production of proinflammatory cytokines in the inflamed intestinal mucosa in Crohn's disease [1-3]. The range of effector $\mathrm{CD}^{+}$subsets has recently expanded with the description of Th17 cells, which produce cytokines IL-17, IL-17F, and IL-22 [4-6]. The proinflammatory cytokines IL-12, which is important for differentiation of Th1 cells, and recently described IL-23 have been shown to play a crucial role in the pathogenesis of CD. Novel studies in murine colitis models resembling human $C D$ suggest that IL-23 is the 
dominant cytokine able to modulate Th17 immune response and to drive the regional intestinal inflammation $[7,8]$.

Studies in mice have shown that different members of NF- $\kappa$ B family play a pivotal role in defense of the host against the pathogens by regulating of proinflammatory gene expression [9]. Synthesis of most important proinflammatory cytokines and chemokines such as IL-12, IL-23, TNF- $\alpha$, IL-6, $\mathrm{IL}-8$, and $\mathrm{IL}-1 \beta$ is mediated by NF- $\mathrm{BB}$. Increased NF-kB activity with nuclear localization was observed in inflammatory bowel disease, especially in CD [10-12]. Proteasome is essential for IKK $\beta$-induced NF- $\mathrm{KB}$ activation contributing directly to the activation of NF- $\mathrm{KB}$ by mediating degradation of inhibitory NF- $\kappa B$ proteins of I $\kappa B$ family and the processing of NF- $\kappa B$ precursor proteins p105 and p100 [13]. Therefore, the proteasome represents a potential target for strategies aimed at suppressing inflammation processes.

The eukaryotic $26 \mathrm{~S}$ proteasome is the main protease in the cytoplasm and nucleus consisting of a proteolytic core, the $20 \mathrm{~S}$ proteasome, and two 19S regulatory particles. The barrel-like $20 \mathrm{~S}$ proteasome is composed of seven different $\alpha$ and seven different $\beta$ subunits which form four rings stacked on top of each other [14]. The subunits $\beta 1, \beta 2$, and $\beta 5$ bear the catalytic activity of the proteasome. In vertebrates, there exist three additional IFN- $\gamma$ inducible subunits, so-called immunosubunits $\beta 1 \mathrm{i}, \beta 2 \mathrm{i}$, and $\beta 5 \mathrm{i}$. IFN- $\gamma$ inducible substitution of proteasomal constitutive subunits by immunosubunits changes the proteolytic specificity of the proteasome and modulates the generation of the peptides used as ligands for MHC class I presentation $[15,16]$. Even more importantly for inflammatory processes, the induction of proteasomal immunosubunits is associated with increased NF-KB activity [11, 17].

It has been shown that the constitutive proteasome is the predominant form in most tissues [18]. In the course of infection, IFN- $\gamma$ induces the expression of immunoproteasomes in affected tissues [19]. Since the levels of IFN- $\gamma$ are also elevated in $\mathrm{CD}$, we decided to evaluate the possible effects of the inflammation on the expression of proteasomes in the intestine. In the present study, the relationship of proteasomal mRNA levels and abundance of encoded proteins in normal and inflamed colonic tissue have been analyzed. In particular, we compared the mRNA and protein expression of proteasomes of patients with $\mathrm{CD}$ with a control group of patients.

\section{Materials and methods}

Patients

Colonic mucosa specimens from patients with Crohn's disease were obtained from surgical resections after intestinal surgery performed at the Charité University Hospital, Berlin. Control specimens were obtained from patients undergoing surgery for colorectal cancer (macroscopically and histologically non-affected normal colonic tissue). A total group of 13 patients with active $\mathrm{CD}$ and 12 control patients was investigated. In all cases, diagnosis of CD was confirmed histologically using scoring systems for CD: $0=$ normal; $1=$ mild edema and mild inflammation in the lamina propria; $2=$ crypt abscesses and moderate inflammation of the lamina propria; 3 = more severe inflammation with destructive crypt abscesses ( \pm granulomata); $4=$ strong inflammation with ulcerations or fissures. Immediately after the surgery, intestinal mucosa was separated from the underlying tissue and used for the experiments. In all $13 \mathrm{CD}$ patients, histology revealed severe inflammation with histological scores of $3(n=7)$ and 4 $(n=6)$, respectively. Informed consent was obtained from all patients, and the protocol was approved by the local ethics committee.

Preparation of protein extracts from human colonic tissue

For the preparation of organ lysates, colonic mucosa was striped from the submucosa, frozen in liquid nitrogen and stored at $-196^{\circ} \mathrm{C}$ until use. Colonic mucosa was homogenized with mortar and pestle followed with 20 strokes of the dauncer and subsequently immersed in ice-cold Lysis Buffer (20 mM Tris-HCl, pH 6,8, $50 \mathrm{mM} \mathrm{NaCl,} 1 \mathrm{mM}$ EDTA pH 8, 1 mM NaN3, 1 mM DTT, 0.1\% NP-40, 0,2 $\mathrm{mM}$ sodium vanadate, $10 \mathrm{mM}$ sodium fluoride, $1 \mathrm{mM}$ PMSF). $1 \times$ complete protease inhibitor (Roche Applied Science, Mannheim, Germany) was added into lysis buffer. Samples were incubated on ice for $20 \mathrm{~min}$ and cell debris was sedimented by centrifugation at $13,000 \times \mathrm{g}$ for $10 \mathrm{~min}$. Supernatants were used as cell lysates.

Western blot analysis

For the detection of proteasomal proteins $\beta 1$ and $\beta 1 \mathrm{i}$, the color fluorescent Western blot analysis was performed. Briefly, for the cell lysates the protein concentration was determined using Micro BCA Protein Assay Kit (Pierce biotechnology, Rockford, IL, USA) and subsequently $20 \mu \mathrm{g}$ of total protein was denaturated in $4 \times$ Laemmli Buffer and separated by $15 \%$ sodium dodecyl sulfate-polyacrylamide gel electrophoresis (SDS-PAGE). Following SDS-PAGE, samples were transferred to Immobilon ${ }^{\mathrm{FL}}$ polyvinylidene difluoride (PVDF) membrane (Millipore, Bedford, MA, USA) at $100 \mathrm{~V}$ in transfer buffer $(50 \mathrm{mM}$ Tris, $40 \mathrm{mM}$ glycine, $0.037 \%(w / v)$ SDS, $20 \%(v / v)$ methanol) for $60 \mathrm{~min}$. Membranes were blocked for $30 \mathrm{~min}$ in an Odyssey Blocking Reagent (Licor Bioscience, Lincoln, NE, USA) and then incubated for $1 \mathrm{~h}$ with the appropriate primary antibody. As control for protein amounts a monoclonal antihuman $\beta$-actin antibody (Sigma-Aldrich, Munich, Germany) diluted 5,000-fold in Odyssey Blocking Reagent was used. $\beta 1$ and $\beta 1 \mathrm{i}$ were detected using rabbit polyclonal anti- 
human antibodies (Biomol, Hamburg, Germany) diluted 1,000 -fold in the same buffer. Visualization was performed by using fluorescence-labeled secondary antibodies, goatanti rabbit IRDye 800 (Rockland, Gilbertsville, PA, USA) and AlexaFluor 680 (Molecular Probes Eugene, OR, USA), respectively. The detection was performed using Odyssey infrared imaging system (Licor Biosciences, Lincoln, NE, USA).

\section{Quantitative real-time PCR}

Quantitative real-time PCR analysis for proteasomal subunits was performed by using an ABI Prism 7000 sequence detection system (Applied Biosystems, Forster city, CA, USA) according to manufacturer's instructions. Primers were manufactured by TIBMolbiol (Berlin, Germany). $\mathrm{AK} 2 \mathrm{C}$ was used as a housekeeping gene for standardization. The analysis was performed as previously described [10]. Briefly, colonic mucosa was homogenized in Trizol (Invitrogen, Carlsbad, CA, USA) and total cellular RNA was extracted and treated with RNase-free DNase in order to remove contaminating genomic DNA from the sample. The determination of concentration and total RNA quality was analyzed with the 2100 Bioanalyzer (Aligent Technologies, Santa Clara, CA, USA). For the cDNA synthesis, $2 \mu \mathrm{g}$ of total RNA was reverse transcribed and subsequently real-time PCR was performed using the SYBR Green Master Mix (Applied Biosystems, Forster city, CA, USA). During PCR reactions, the increase in SYBR Green fluorescence is directly proportional to the amount of double-stranded DNA generated; $5 \mu 1$ cDNA template diluted 1:5 and 1:10,10 pmol forward primer, $10 \mathrm{pm}$ reverse primer and SYBR Green Mix ready-to-use solution $(2 \times)$ in a $30 \mu \mathrm{l}$ final reaction mixture were used. The evaluation of data was carried out by using SDS2.2.2. software (Applied Biosystems, Forster city, CA, USA).

Immunofluorescence microscopy

Immunoflourescence staining was performed on intestinal cryosections of $5 \mu \mathrm{m}$ thickness. For intracellular staining of proteasome subunit $\beta 1 \mathrm{i}$, the sections were washed in PBS for $5 \mathrm{~min}$, fixed in acetone /methanol (1:1) and permeabilized with $0.1 \%(v / v)$ NP40 for $10 \mathrm{~min}$. After permeabilization, normal goat serum was applied for binding nonspecific antigens. As primary antibody, polyclonal rabbit anti- $\beta 2 \mathrm{i}$ (Biomol, Hamburg, Germany) diluted 1:50 was used for $60 \mathrm{~min}$. As negative control, sections were incubated with antibody diluent without primary antibody. $\beta 2 \mathrm{i}$ was detected using secondary Cy2-coupled anti-rabbit immunoglobulin G (DakoCytomation, Hamburg, Germany) for $60 \mathrm{~min}$. The sections were analyzed on the fluorescence microscope Leica DMRB (Leica Microsystems, Wetzler, Germany).
Statistical analysis

Real-time PCR data were compared using a two-tailed Student's $t$-test. A one-way ANOVA was used for analyzing multiple groups. Each set of data was expressed as SEM. $P$ values $\leq 0.05$ were regarded as statistically significant.

\section{Results}

Preferential incorporation of proteasomal immunosubunit $\beta 1 \mathrm{i}$ in Crohn's disease

A previous study has shown that DSS treatment induced increased expression of $\beta 1 \mathrm{i}$ in the colon associated with histological damage in mice, whereas symptoms of DSSinduced colitis were much milder in $\beta 1 \mathrm{i}$-deficient $\left(\mathrm{LMP}^{-/-}\right)$ mice lacking the $\beta 1 \mathrm{i}$ subunit [20]. To investigate the incorporation of distinct proteasomal catalytic subunits into proteasomes of CD patients, intestinal samples were examined by Western blotting and real-time PCR. In inflamed colon of patients with $\mathrm{CD}$ and non-inflamed colonic tissue of control patients, the abundance of the catalytic immunosubunit $\beta 1 \mathrm{i}$ was examined by Western blot analysis. By using specific antibody for $\beta 1 \mathrm{i}$, a singular band for this protein was detected at approximately $25 \mathrm{kD}$. The increased protein expression of $\beta 1 \mathrm{i}$ was observed in patients with $\mathrm{CD}$ as compared to control patients (Fig. 1b). In order to analyze whether the increased incorporation of immunosubunit $\beta 1 \mathrm{i}$ into proteasomes in inflamed colonic mucosa of CD patients is the limiting factor for the expression of its counterpart protein $\beta 1$, the whole cell lysates from colonic tissue of CD and control patients were also tested for $\beta 1$. In all but one control patients, the protein levels of this constitutive proteasomal subunit were higher in control tissue than in inflamed colonic tissue of patients with CD (Fig. 1a). Thus, the increase of the $\beta 1 \mathrm{i}$ protein levels in $\mathrm{CD}$ was accompanied with a significantly decreased abundance of $\beta 1$ (Fig. 1a and b).

Inflammation in Crohn's disease shifts the proteasome subunit composition towards immunoproteasomes

Since immunoproteasome subunits compete with their constitutive homologues for incorporation into the nascent proteasomes, we wondered whether mRNA levels of catalytic subunits $\beta 1 \mathrm{i}$ and $\beta 1$ correlate with protein expression in CD. To study this, total RNA was extracted from colonic samples of CD patients and healthy controls and $\beta 1$ and $\beta 1 \mathrm{i}$ mRNAs were quantified by quantitative real-time PCR. At the same time, we looked at the $\beta 1 \mathrm{i} / \beta 1$ ratio of their cellular mRNA levels in CD and controls. In the inflamed mucosa of CD patients, we observed an increase of $\beta 1 \mathrm{i}$ mRNA levels compared with normal 


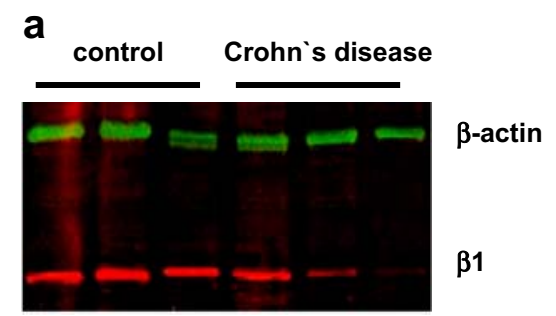

Fig. 1 Protein expression of the proteasomal subunits $\beta 1$ (a) and $\beta 1 \mathrm{i}$ (b) in the inflamed mucosa of CD patients and normal colonic tissue (control, $n=12 ; \mathrm{CD}, n=13$ ). Western blot analysis was performed using anti-human antibodies for $\beta 1 \mathrm{i}$ and $\beta 1$. $\beta$-actin was used as

mucosa (Fig. 2a). By analyzing the ratio of immunosubunit $\beta 1 \mathrm{i}$ mRNA to its counterpart $\beta 1$ mRNA, we observed that in inflamed tissue of $\mathrm{CD}$ patients, threefold more $\beta 1 \mathrm{i}$ mRNA was expressed relative to the $\beta 1$ mRNA, whereas no significant difference in the expression of $\beta 1 \mathrm{i}$ and $\beta 1$ mRNA was observed in normal colonic tissue (Fig. 2b). These results indicate that due to inflammation significantly increased expression of $\beta 1 \mathrm{i}$ mRNA leads to augmented amounts of $\beta 1$ i protein and that induced overexpression of $\beta 1 \mathrm{i}$ prevents incorporation of its constitutive counterpart $\beta 1$ into 20S proteasomes in $\mathrm{CD}$.

Interestingly, not only mRNA levels of $\beta 1 \mathrm{i}$ but also of $\beta 5 \mathrm{i}$ were enhanced in $\mathrm{CD}$ in comparison to control colonic tissue. However, $\beta 5 \mathrm{i}$ mRNA expression was also very high in normal colonic tissue (Fig. 3a). By examining ratio of $\beta 5 \mathrm{i} / \beta 5 \mathrm{mRNA}$ in patients with $\mathrm{CD}$ and control patients, we found that mRNA expression of $\beta 5 \mathrm{i}$ was approximately fourfold higher than that of mRNA $\beta 5$ in both groups (Fig. 3b). Previously, our proteasome analysis of distinct mouse and human organs by using two-dimensional gel electrophoresis and mass spectrometry has revealed high amounts of $\beta 5 \mathrm{i}$ in normal human intestine [21]. In accordance with this study, we here detected high $\beta 5 \mathrm{i}$

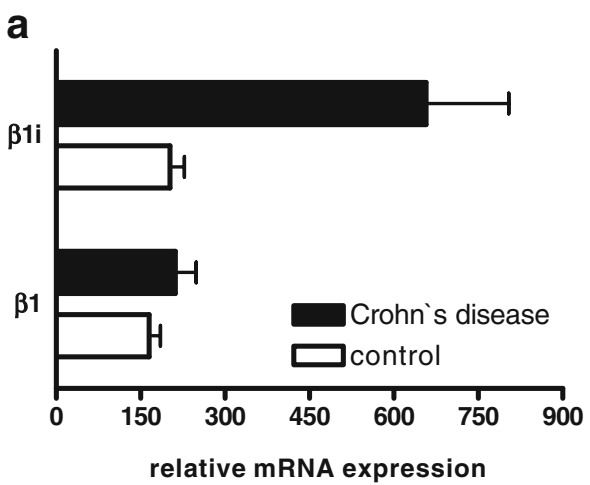

Fig. 2 a Relative mRNA expression of proteasomal subunits $\beta 1 \mathrm{i}$ and $\beta 1$ was analyzed in the colon of controls and $\mathrm{CD}$ patients by quantitative real-time PCR. Data represents means \pm SEM (control, $n=12 ; \mathrm{CD}, n=13)$. After extraction of total RNA, cDNA was

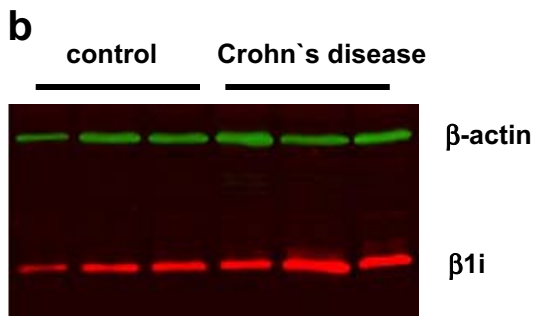

loading control. The results shown above are from three representative patients. Lanes 1-3, cell extracts of normal colonic mucosa; lane 4-6, cell extracts of inflamed colonic mucosa of CD patients

mRNA levels in both inflamed colon of CD and control non-inflamed colonic tissue, although mRNA expression of this immunosubunit was even higher in CD (Fig. 3a).

Expression of immunosubunit $\beta 2 \mathrm{i}$ is increased in Crohn's disease

$\beta 2 \mathrm{i}$ is the third inducible catalytic subunit, which has been shown to be preferentially incorporated into the imunoproteasome [22]. To confirm that the immunoproteasome is predominant form of proteasomes in inflamed colonic mucosa of patients with $\mathrm{CD}$ we analyzed the protein expression of the immunosubunit $\beta 2 \mathrm{i}$ using a polyclonal rabbit antibody detected by immunofluorence staining. Analysis of colonic mucosa showed that the lamina propria cells as well as epithelial cells of the inflamed tissue in CD were positive after staining of $\beta 2 \mathrm{i}$. No $\beta 2 \mathrm{i}$ expressing positive cells were visualized in normal colon (Fig. 4). Thus, we demonstrate here that all three inducible proteasomal immunosubunits are highly expressed in colonic mucosa of patients with $\mathrm{CD}$ but not in that of control patients. The $\beta 5 \mathrm{i}$ was the only immunosubunit also abundant in normal colon, which indicates that also

b

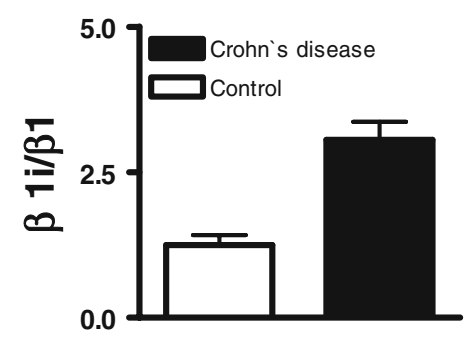

amplified with specific primers for $\beta 1 \mathrm{i}$ and $\beta 1$. As housekeeping gene, $\mathrm{AK} 2 \mathrm{C}$ was used. b Ratio of $\beta 1 \mathrm{i}$ to $\beta 1 \mathrm{mRNA}$ expression in colonic mucosa of controls and CD patients (control, $n=12$; CD, $n=13$ ). Data are presented as means \pm SEM 

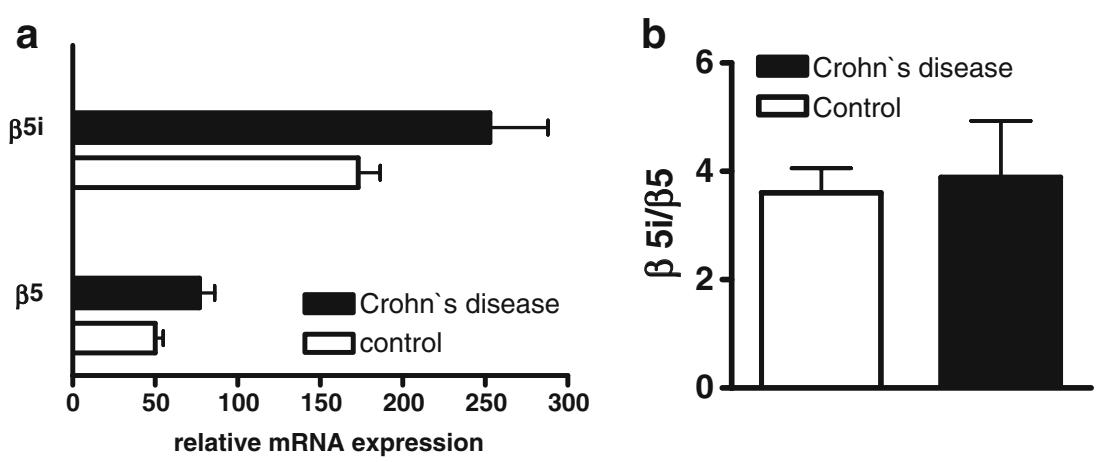

Fig. 3 a Relative mRNA expression of proteasomal subunits $\beta 5 i$ and $\beta 5$ measured in the colonic mucosa of control and $\mathrm{CD}$ patients (control, $n=12 ; \mathrm{CD}, n=13$ ). The results are presented as mean $\pm \mathrm{SEM}$. Quantitative real-time PCR was performed using specific primers for

different, more heterogeneous proteasome populations exist which may have different functions in vivo.

\section{Discussion}

There is increasing evidence that primary dysregulation of the mucosal immune system is one of the most important factors in the development of $\mathrm{CD}$ [23]. Inappropriate secretion of proinflammatory cytokines and other inflammation mediators by intestinal macrophages, dendritic cells and $\mathrm{T}$ cells has been shown to be responsible for the immune disturbance in $\mathrm{CD}[24,25]$. The activation of the transcription factor NF- $\mathrm{KB}$ plays a pivotal role in responses to inflammatory signaling through Toll-like receptors, TNF receptor superfamily and the IL-1 receptor [26]. While some events triggering the induction of NF- $\mathrm{kB}$ activity remain still obscure, it is well-known that ubiqutin-proteasome system contributes directly to activation of this transcription factor - and thus to many aspects of inflammatory responses. The core particle of the enzymatically active $26 \mathrm{~S}$ proteasome

Fig. 4 Immunofluorescence analysis of proteasomal immunosubunit $\beta 2 \mathrm{i}$ in the colon of $\mathrm{CD}$ patients and controls (control, $n=12$; CD, $n=13$ ).

Representative images of staining for $\beta 2 \mathrm{i}$, magnification, $\times 200$. Increased expression of $\beta 2 \mathrm{i}$ was observed in $\mathrm{CD}$ patients

$\beta 5 \mathrm{i}$ and $\beta 5$. As housekeeping gene, AK2C was used. b $\beta 1 \mathrm{i} / \beta 1$ mRNA expression in inflamed colonic tissue of $\mathrm{CD}$ patients and control colon tissue (control, $n=12 ; \mathrm{CD}, n=13$ ). Data are presented as means \pm SEM

is the $20 \mathrm{~S}$ proteasome, a multicatalytic complex composed of 14 different subunits. The two inner rings are formed by the $\beta$-type subunits, of which $\beta 1, \beta 2$, and $\beta 5$ are catalytically active sites [16]. It has been shown that interferon- $\gamma$ (IFN$\gamma$ ), the most important cytokine during viral infection, is the central molecule causing the alternation of the proteasomal subunit composition. Upon stimulation of cells with IFN- $\gamma$, the constitutive catalytic subunits $\beta 1, \beta 2$ and $\beta 5$ are replaced with $\beta 1 \mathrm{i}, \beta 2 \mathrm{i}$ and $\beta 5 \mathrm{i}$, respectively. This replacement of constitutive proteasomes with so-called immunoproteasomes is a way that can promote more efficient generation of epitopes from viral- and tumor-associated antigens suitable for binding to MHC class I molecules [27].

For many years IFN- $\gamma$ has been considered to be one of the most important cytokines involved in the pathogenesis of $\mathrm{CD}[25,28]$. The aim of this study was to investigate the expression of IFN- $\gamma$ - inducible proteasome immunosubunits both at the mRNA and protein level in the inflamed intestinal mucosa of CD patients. Despite the considerable variations between individual samples, we were able to find

DAPI
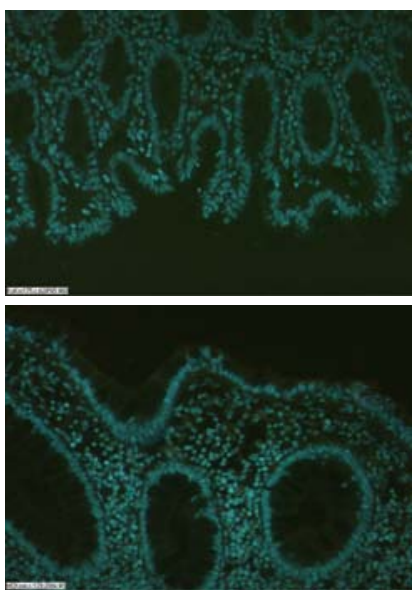

$\beta 2 \mathbf{i}$

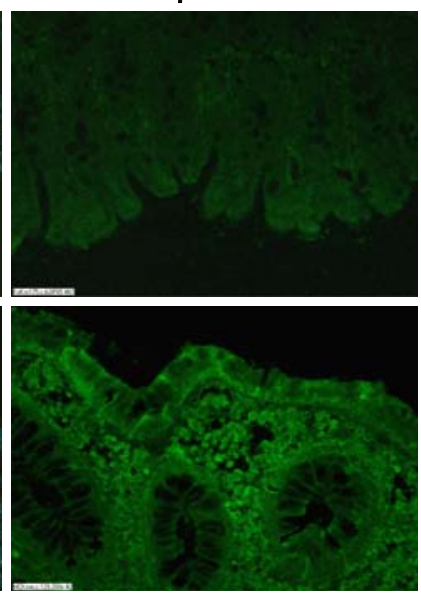

Crohn`s disease

control

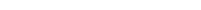


significant changes in colonic mucosa of patients with $\mathrm{CD}$ when compared with control patients. Inflamed tissue of patient with $C D$ showed markedly increased levels of immunoproteasomes. An important finding of this study is the pronouncedly high mRNA expression of all three immunosubunits $\beta 1 \mathrm{i}, \beta 2 \mathrm{i}$ and $\beta 5 \mathrm{i}$ in $\mathrm{CD}$. Interestingly, at the mRNA level, inflammation induces not only immunosubunits but to less extent also constitutive catalytic subunits. However, the induction of immunosubunit mRNAs was significantly stronger resulting in the replacement of constitutive proteasomal proteins by their homologous counterparts. Western blot analysis of the subunits $\beta 1 \mathrm{i}$ and $\beta 1$ clearly showed that the chronic inflammation in Crohn's disease shifts the proteasome subunit expression towards immunoproteasomes at the protein level. Since IFN- $\gamma$ has been shown to be the main inducer of immunoproteasomes in various murine and human cell lines and the IFN- $\gamma$ levels are highly elevated in inflamed intestine of CD patients, we suppose that induction of immunoproteasomes in $\mathrm{CD}$ is mediated by this cytokine. However, relatively high constitutive expression of mRNA $\beta 5 \mathrm{i}$ was also observed in the control colonic tissue. In accordance with this finding, it has been previously demonstrated that beyond homogenous subtypes of constitutive and immunoproteasomes, also mixed proteasome forms exist in various mouse and human tissues $[21,29]$.

A major question is whether the difference in proteasome expression we observed in inflamed mucosa of CD patients has a strong functional implication in vivo. Many reports have shown that proteasomes are involved in regulation of various proteins important for distinct cellular functions $[30,31]$. The replacement of constitutive proteasomes by immunoproteasomes has been reported to be crucial for the generation of active NF-KB subunits [17]. Although it has been demonstrated that the immunosubunits $\beta 1 \mathrm{i}$ was essential for the processing of NF-KB precursor protein $\mathrm{p} 105$ and for the degradation of the inhibitory protein $\mathrm{I} \mathrm{K} \mathrm{B} \alpha$ in human lymphocytes, little is known about the regulating NF- $\mathrm{KB}$ activity by the specific proteasomal subunits. Previously, we have shown that active $20 \mathrm{~S}$ proteasomes purified from the inflamed intestine of $\mathrm{CD}$ patients efficiently degraded the inhibitory NF-KB protein I $K B \alpha$ [11]. This data, together with the present study, suggest that expression and activity of immunoproteasomes in the inflamed intestine of $\mathrm{CD}$ patients might be involved in the mechanisms underlying immunopathogenesis of this disease.

In conclusion, our results demonstrate that the development of chronic intestinal inflammation in $\mathrm{CD}$ leads to alternations in the subunit composition of $20 \mathrm{~S}$ proteasomes. Inflamed colonic tissue of patients with $\mathrm{CD}$ showed a characteristic pattern of $20 \mathrm{~S}$ proteasomes which was different from control tissue. Markedly increased mRNA expression and high protein amounts of immunosubunits were found in $\mathrm{CD}$ as compared to control patients. Although this finding shows significant effects of Th1/ Th17-mediated inflammation on the composition of proteasomes, further studies including induction of colitis in $\beta 1 \mathrm{i}$, $\beta 2 \mathrm{i}$, and $\beta 5 \mathrm{i}$ deficient mice are needed to determine physiological importance of this proteasomal shift. We suppose that immunoproteasome subunits might be involved in the complex inflammatory response during the chronic inflammation by increasing NF-KB activity.

Acknowledgements This work was supported by Sonderforschungsbereich 633 (Berlin, Germany). We thank D. Seidel for supporting the quantitative real-time PCR analysis as well as D. Oberbeck-Mueller and P. Krienke for technical help.

Open Access This article is distributed under the terms of the Creative Commons Attribution Noncommercial License which permits any noncommercial use, distribution, and reproduction in any medium, provided the original author(s) and source are credited.

\section{References}

1. Xavier RJ, Podolsky DK (2007) Unravelling the pathogenesis of inflammatory bowel disease. Nature 448:427-434

2. Atreya R, Neurath MF (2008) New therapeutic strategies for treatment of inflammatory bowel disease. Mucosal Immunol $1: 175-182$

3. Wirtz S, Neurath MF (2000) Animal models of intestinal inflammation: new insights into the molecular pathogenesis and immunotherapy of inflammatory bowel disease. Int J Colorectal Dis $15: 144-160$

4. Mangan PR, Harrington LE, O'Quinn DB, Helms WS, Bullard DC, Elson CO, Hatton RD, Wahl SM, Schoeb TR, Weaver CT (2006) Transforming growth factor-beta induces development of the $\mathrm{T}(\mathrm{H}) 17$ lineage. Nature 441:231-234

5. Bettelli E, Carrier Y, Gao W, Korn T, Strom TB, Oukka M, Weiner HL, Kuchroo VK (2006) Reciprocal developmental pathways for the generation of pathogenic effector TH17 and regulatory T cells. Nature 441:235-238

6. Bettelli E, Korn T, Oukka M, Kuchroo VK (2008) Induction and effector functions of T(H) 17 cells. Nature 453:1051-1057

7. Hue S, Ahern P, Buonocore S, Kullberg MC, Cua DJ, McKenzie BS, Powrie F, Maloy KJ (2006) Interleukin-23 drives innate and $\mathrm{T}$ cell-mediated intestinal inflammation. $\mathrm{J}$ Exp Med 203:2473-2483

8. Yen D, Cheung J, Scheerens H, Poulet F, McClanahan T, McKenzie B, Kleinschek MA, Owyang A, Mattson J, Blumenschein W, Murphy E, Sathe M, Cua DJ, Kastelein RA, Rennick D (2006) IL-23 is essential for T cell-mediated colitis and promotes inflammation via IL-17 and IL-6. J Clin Invest 116:1310-1316

9. Bonizzi G, Karin M (2004) The two NF-kappaB activation pathways and their role in innate and adaptive immunity. Trends Immunol 25:280-288

10. Schreiber S, Nikolaus S, Hampe J (1998) Activation of nuclear factor kappa B inflammatory bowel disease. Gut 42:477-484

11. Visekruna A, Joeris T, Seidel D, Kroesen A, Loddenkemper C, Zeitz M, Kaufmann SH, Schmidt-Ullrich R, Steinhoff U (2006) Proteasome-mediated degradation of IkappaBalpha and processing of p105 in Crohn disease and ulcerative colitis. J Clin Invest 116:3195-3203 
12. Schottelius AJ, Baldwin AS Jr (1999) A role for transcription factor NF-kappa B in intestinal inflammation. Int J Colorectal Dis $14: 18-28$

13. Hayden MS, Ghosh S (2004) Signaling to NF-kappaB. Genes Dev $18: 2195-2224$

14. Groll M, Heinemeyer W, Jager S, Ullrich T, Bochtler M, Wolf DH, Huber R (1999) The catalytic sites of 20S proteasomes and their role in subunit maturation: a mutational and crystallographic study. Proc Natl Acad Sci U S A 96:10976-10983

15. Rock KL, York IA, Saric T, Goldberg AL (2002) Protein degradation and the generation of MHC class I-presented peptides. Adv Immunol 80:1-70

16. Kloetzel PM (2004) The proteasome and MHC class I antigen processing. Biochim Biophys Acta 1695:225-233

17. Hayashi T, Faustman D (2000) Essential role of human leukocyte antigen-encoded proteasome subunits in NF-kappaB activation and prevention of tumor necrosis factor-alpha-induced apoptosis. J Biol Chem 275:5238-5247

18. Kuckelkorn U, Ruppert T, Strehl B, Jungblut PR, Zimny-Arndt U, Lamer S, Prinz I, Drung I, Kloetzel PM, Kaufmann SH, Steinhoff U (2002) Link between organ-specific antigen processing by $20 \mathrm{~S}$ proteasomes and CD8(+) T cell-mediated autoimmunity. J Exp Med 195:983-990

19. Khan S, van den BM, Schwarz K, de Giuli R, Diener PA, Groettrup M (2001) Immunoproteasomes largely replace constitutive proteasomes during an antiviral and antibacterial immune response in the liver. J Immunol 167:6859-6868

20. Fitzpatrick LR, Khare V, Small JS, Koltun WA (2006) Dextran sulfate sodium-induced colitis is associated with enhanced low molecular mass polypeptide 2 (LMP2) expression and is attenuated in LMP2 knockout mice. Dig Dis Sci 51:1269-1276
21. Visekruna A, Joeris T, Schmidt N, Lawrenz M, Ritz JP, Buhr HJ, Steinhoff U (2008) Comparative expression analysis and characterization of $20 \mathrm{~S}$ proteasomes in human intestinal tissues: The proteasome pattern as diagnostic tool for IBD patients. Inflamm Bowel Dis

22. Griffin TA, Nandi D, Cruz M, Fehling HJ, Kaer LV, Monaco JJ, Colbert RA (1998) Immunoproteasome assembly: cooperative incorporation of interferon gamma (IFN-gamma)-inducible subunits. J Exp Med 187:97-104

23. Strober W, Fuss I, Mannon P (2007) The fundamental basis of inflammatory bowel disease. J Clin Invest 117:514-521

24. Bouma G, Strober W (2003) The immunological and genetic basis of inflammatory bowel disease. Nat Rev Immunol 3:521-533

25. Neurath MF, Finotto S, Glimcher LH (2002) The role of Th1/Th2 polarization in mucosal immunity. Nat Med 8:567-573

26. Ghosh S, Karin M (2002) Missing pieces in the NF-kappaB puzzle. Cell 109(Suppl):S81-S96

27. Kruger E, Kuckelkorn U, Sijts A, Kloetzel PM (2003) The components of the proteasome system and their role in MHC class I antigen processing. Rev Physiol Biochem Pharmacol 148:81104

28. Stallmach A, Giese T, Schmidt C, Ludwig B, Mueller-Molaian I, Meuer SC (2004) Cytokine/chemokine transcript profiles reflect mucosal inflammation in Crohn's disease. Int J Colorectal Dis 19:308-315

29. Dahlmann B, Ruppert T, Kuehn L, Merforth S, Kloetzel PM (2000) Different proteasome subtypes in a single tissue exhibit different enzymatic properties. J Mol Biol 303:643-653

30. Adams J (2004) The proteasome: a suitable antineoplastic target. Nat Rev Cancer 4:349-360

31. Elliott PJ, Zollner TM, Boehncke WH (2003) Proteasome inhibition: a new anti-inflammatory strategy. J Mol Med 81:235-245 